\title{
Se a aula é de poesia, que tal uma experiência literária com o Poetry Slam?
}

\author{
It is classroomed by poetry, what such a \\ literary experience as a poetry slam?
}

\author{
João Ricardo Vieira Santos Ribeiro ${ }^{1}$ \\ Kátia Rodrigues Mello Miranda ${ }^{2}$
}

\section{Resumo:}

A importância da poesia para o desenvolvimento do ser e da sociedade é consenso no meio educacional, entretanto, pesquisas (PINHEIRO, 2007; GEBARA, 2002), dentre outras, certificam a pouca expressividade do seu ensino para a formação literária dos alunos. Em face dessa constatação, e sem a intenção de negar o valor do cânone ou reverberar uma discussão já recorrente a seu respeito, nosso objetivo é, de maneira geral, refletir sobre o corpus de produções líricas selecionado pela escola, o qual concordamos que precisa ser ampliado. Para isso, como alternativa para um trabalho significativo com a poesia em sala de aula, apresentamos o Poetry Slam, que, nos últimos anos, vem ganhando espaço na esfera de manifestações literárias orais, por meio das suas chamadas "batalhas" de poesias faladas, nas quais os autores declamam de maneira performática seus textos, no tempo de três minutos, sem o uso de recursos cênicos. Considerando a viabilidade do ensino do slam, sob a ótica do letramento literário, propomos uma sequência básica, elaborada com base nos pressupostos de Cosson (2014) e passível de

1 Graduado em Letras com habilitação Espanhol pela Universidade Estadual Paulista Júlio de Mesquita Filho, UNESP, Assis, SP, Brasil.

2 Professora Assistente Doutora do Departamento de Letras Modernas - Área de Espanhol, da Universidade Estadual Paulista UNESP, Assis, SP, Brasil. 
aplicação no Ensino Médio, que, dentre outras possibilidades, resulte no combate ao racismo e empoderamento individual dos alunos.

Palavras-chave: Poetry Slam. Ensino de Poesia. Proposta didática.

\section{Abstract:}

The importance of poetry for the development of being and society is a consensus in the educational environment; however, research certifies the little expressiveness of its teaching for the literary formation of students. In view of this observation, and without denying the value of the canon or echoing an already recurring discussion about it, our objective is, in general, to reflect on the corpus of lyrical productions selected by the school, which we agree needs to be expanded. For this, as an alternative to meaningful work with poetry in the classroom, we present Poetry Slam, which in recent years has been gaining space in the sphere of oral literary manifestations, through its so-called battles of spoken poetry, in which the authors they decree in a performative way their texts, in the time of three minutes, without the use of scenic resources. Considering the feasibility of teaching slam, from the perspective of literary literacy, we propose a basic sequence, elaborated based on the assumptions of Cosson (2014) and capable of application in high school, which, among other possibilities, results in the fight against racism and empowerment individual students.

Keywords: Poetry Slam. Teaching of Poetry. Teaching proposal.

\section{Palavras iniciais}

Quando averiguamos a origem do gênero lírico, notamos que, na Antiguidade Clássica (entre os séculos VIII a.C. e V d.C.), já havia produções poéticas, bem como a contemplação de seus sentidos. Ao longo do tempo, o conceito de gênero poético assumiu acepções diversas, mas a sua existência sempre permaneceu. Platão, por exemplo, considerava a poesia 
como a imitação da imitação. Para ele, o mundo das ideias era a representação de um mundo perfeito. Já a área sensível do mundo, a parte que nos cerca, seria uma imitação deformada do real; por isso, "a poesia, cópia do mundo sensível que, por sua vez, copia o mundo das ideias, [seria a] cópia da cópia, sinônimo de imperfeição" (MARTHA, 2015, p. 115).

Em Aristóteles, a poesia ganha valor ao ser considerada uma imitação ou recriação da realidade. Para ele, o motivo do seu aparecimento deve-se à natureza humana que tende à imitação e ao gosto pela harmonia e pelo ritmo. Diante disso, a função do poeta seria a de "recriar o real, captando-o e humanizando-o" (MARTHA, 2015, p. 115). Horácio, por sua vez, conferiu à poesia um caráter moralizante e didático ao unir prazer e educação. Em sua concepção, caberia ao poeta respeitar as particularidades de cada gênero, "devendo haver adequação entre assunto e ritmo, tom e metro" (MARTHA, 2015, p. 115).

Depois desses pensadores, vieram muitos outros estudiosos, inclusive com uma perspectiva oposta a essas reflexões iniciais. A título de exemplo, apesar de a concepção horaciana ainda ser muito presente no ensino do gênero poético, Pinheiro (2007) defende que não se deve esperar da poesia uma função social moralizante, pois o que ela pode gerar no ser humano não pode ser mensurado em modelos esquemáticos, já que estamos tratando de uma experiência íntima, profunda do ser.

Nesse mesmo entendimento sobre a função social da poesia, Martha $(2015$, p. 117) ratifica que a "sensibilidade, veiculada nas composições poéticas, transforma-se em poderoso auxiliar para a organização do mundo interior do ser humano [...]". Paixão (1984, p. 41) acrescenta, ainda, que a leitura de poesia "nos ensina a olhar e sentir" não mais por meio de "lições de certezas, estáticas", mas desperta a verdadeira "vivência dinâmica e sensível do real".

Eliot (1972), por sua vez, afirma ser a capacidade de proporcionar prazer a primeira função da poesia. No entanto, para além do prazer, "há 
sempre a comunicação de alguma experiência nova, de algum entendimento novo do familiar, ou a expressão de alguma coisa que sentimos mas para a qual não temos palavras, que amplia nossa conscientização ou apura nossa sensibilidade" (ELIOT, 1972, p. 32). Dentro dessa habilidade de apurar os sentimentos individuais, o crítico literário inglês destaca a capacidade de influência do poeta tanto na linguagem quanto na sensibilidade de sua própria nação. De acordo com seu ponto de vista, o escritor tem um dever com a sua língua e, por meio de seus escritos, pode preservá-la, assim como ampliá-la e melhorá-la. Como consequência, a cultura que não produzir novos poetas acabará se deteriorando e, em casos mais sérios, sendo absorvida por outra mais forte:

\begin{abstract}
Nossa língua muda; nosso modo de vida muda sob a pressão das várias modificações materiais do meio ambiente; e a não ser que tenhamos aqueles poucos homens que aliam uma sensibilidade excepcional a um excepcional domínio das palavras, nossa própria habilidade, não apenas de expressão, mas de sentir algo mais do que as mais simples emoções, degenerará (ELIOT, 1972, p. 37).
\end{abstract}

Percebe-se, de tal maneira, que a poesia, além de apresentar conteúdo social e estético capaz de modificar os sujeitos que dela se aproximam, corrobora paralelamente, afigura do poeta, como um gênero imprescindível para o desenvolvimento da sociedade. Diante disso depreendem-se, pelo menos, três questionamentos: em primeiro lugar, dada a sua importância, qual tem sido o lugar da poesia na vida dos brasileiros? Em segundo, qual tem sido o trabalho por parte da escola para incentivar a leitura e a produção do gênero poético? Por último, ainda no que tange ao ensino escolar, sem negar o espaço e o valor do cânone, o estudo da literatura está sendo ampliado, compreendendo manifestações poéticas diversas, como o Poetry Slam?

Considerando esses questionamentos, inicialmente discutimos a presença da poesia na vida de estudantes e não estudantes bem como 
na esfera educacional. Em seguida, nosso foco volta-se à conceituação e contextualização panorâmica do Poetry Slam, movimento poético oral e performático, de caráter político e social, capaz de debater não só temas aliados a causas sociais mas também a refletir sobre a viabilidade de sua presença nas aulas de literatura. Na seção seguinte, propomos uma sequência básica para o ensino do slam, com base nas etapas sugeridas por Cosson (2014), na perspectiva do letramento literário, com a finalidade de contribuir com ideias de práticas possíveis em sala de aula que propiciem um aprendizado crítico e humanizador da literatura, na medida em que promove a aproximação do aluno com contextos sociais reais.

\section{Da escola à vida: qual o espaço da poesia na sociedade?}

Para refletir sobre o espaço da poesia na sociedade, recorremos aos resultados da obra Retratos da leitura no Brasil $^{4}$ (FAILLA, 2016), em que o gênero poético encontra-se em $7^{\circ}$ lugar no que se refere ao tipo de leitura feita por crianças, jovens e adultos, com $12 \%$ do valor total. Com isso, tal gênero fica atrás de outros seis: a Bíblia (42\%), os livros religiosos (22\%), os contos $(22 \%)$, os romances (22\%), os livros didáticos $(16 \%)$ e as histórias em quadrinhos, gibis ou RPG (15\%). Por outro lado, a pesquisa mostra, também, que a escolha pela poesia caiu em relação à edição anterior, visto que, em 2011, 20\% dentre os pesquisados apreciavam sua leitura.

De acordo com o mesmo estudo, a leitura poética é maior entre os estudantes (17\%) do que entre os não estudantes (9\%). Dentro do ambiente escolar, o ápice do número de leitores encontra-se no Ensino Fundamental II (14\%) e no Ensino Médio (13\%), com índices muito baixos no Ensino Fundamental I (9\%) e Ensino Superior (11\%). Dessa forma, percebe-se que a escola vem fracassando na formação de leitores de poesia, dado que, enquanto estão no ambiente escolar, são poucos os alunos que mostram preferência pela poesia, e, depois de formados, nota-se que ela deixa de ser 
de uma opção de leitura em suas vidas (VIANA, 2018).

Um motivo para isso deve-se, de acordo com Pinheiro (2007), à própria ausência da poesia na sala de aula, apesar de sua boa receptividade, principalmente, pelo público infantil. A dificuldade começa pelo fato de os professores se acharem despreparados para trabalhar com esse gênero. Sob tal prisma, os docentes das séries iniciais do Ensino Fundamental $\left(1^{\circ}\right.$ ao $5^{\circ}$ ano) priorizam os textos em prosa e, quando trabalham com a poesia, o fazem a seguindo os moldes existentes nos livros didáticos. Nas séries seguintes, apesar de os professores serem formados em Letras e terem um suposto conhecimento na área de interpretação do texto poético, não se observa, em geral, a busca em despertar o gosto dos alunos pela leitura do gênero, tendo em vista que, na maioria dos casos, os próprios docentes não são leitores de poesia (PINHEIRO, 2007; DANTAS, 2019).

Pinheiro (2007) acrescenta que não há obras poéticas voltadas, especificamente, ao público juvenil, algo que compromete, ainda mais, o trabalho dos professores desse segmento, que não são acostumados a ler poesia. Nessa esteira, temos ainda o Currículo do Estado de São Paulo (SÃO PAULO, 2011), que, ao apoiar-se em um ideal neoliberal, acaba considerando, no processo de ensino, apenas os gêneros vistos como úteis para um possível ingresso dos alunos no mercado de trabalho (VIANA, 2018). Isso, por consequência, distancia a escolha da poesia, uma vez que, na concepção do mundo ocidental, ela é vista, em linhas gerais, como um passaporte para pessoas desocupadas, loucas, que vivem no mundo nas nuvens, de acordo com Walty (1994).

Outra barreira encontra-se no pré-julgamento que existe por parte de professores e alunos em considerar a poesia uma produção de difícil compreensão, no sentido de requerer um conhecimento teórico acima do que a escola poderia oferecer em relação à métrica, estrofe, figuras linguagem e rimas. Nessa visão, consequentemente, somente pessoas acima da média poderiam escrever ou ler adequadamente esse gênero. Assim, Moi- 
sés (1996, p. 17) afirma que "para gostar de poesia é preciso lutar contra toda sorte de preconceitos, os 'conservadores' e os 'avançados', e é preciso também estar sempre disposto a enfrentar com humildade as surpresas e armadilhas que ela abriga, em suas formas inumeráveis".

A esse respeito, cabe esclarecer que a linguagem poética tem suas particularidades. Ela se distingue-se da prosa, por exemplo, pelo seu alto "poder de síntese, pela infinita variedade de seus expedientes e pela capacidade que tem o poeta de falar nas entrelinhas" (MOISÉS, 1996, p. 12). Por conseguinte, sua leitura exige um tempo diferente do imediatismo presente na linguagem prática, racional e objetiva.

Por sua vez, quando ocorre algum trabalho pedagógico com o gênero, no momento da alfabetização, a poesia é apresentada aos alunos pelo caminho da sonoridade ou do humor, visto que há "um pendor infantil para o ritmo tanto sonoro quanto corporal" (GEBARA, 2002, p. 142). Do $6^{\circ}$ ano em diante, o espaço lúdico é diminuído e, consequentemente, o da poesia também. $\mathrm{O}$ motivo para isso encontra-se no fato de a poesia ser percebida apenas como uma atividade lúdica e, como "a escola é o lugar da seriedade [...] não se pode perder tempo com uma linguagem que não pertence ao mundo da prática" (GEBARA, 2002, p. 146). Por isso, quando ela reaparece no $8^{\circ}$ ano, o trabalho ocorre somente pela temática, que, caso seja sempre a mesma, não propiciará a ampliação das perspectivas de leitura dos alunos (PINHEIRO, 2007).

Quanto ao teor das atividades, percebe-se que o ensino da poesia, na maioria das vezes, tem assumido uma função meramente pedagógica, sendo pretexto para o ensino de aspectos gramaticais ou um meio para se adquirir novos vocabulários. Em certos momentos, o gênero chega a ser usado apenas em datas comemorativas para ilustrar cartões ou ser objeto de declamação por parte dos alunos. Por sua vez, quando se volta o estudo para a linguagem, o poema acaba sendo posto em semelhança com outros gêneros primários, como a bula de remédio, a receita e o bilhete (GRASSI, 
2015).

Os textos escolhidos, por outro lado, são os que se engradam no conceito de cânone literário, ou seja, correspondem aos que apresentam um renomado valor estético e cultural, presentes no gosto estético erudito da elite intelectual. Por consequência, a preferência dos alunos acaba sendo deixado de lado e, até mesmo, "estigmatizado. Quando isso acontece, a escola parece desconsiderar que, na definição do cânone literário, existem muitas controvérsias, principalmente no que se refere aos critérios estabelecidos para inclusão - ou não - das obras nessa classificação (BUSE, 2011).

Embora o objetivo aqui não seja discutir a formação do cânone em suas diferentes nuances e, tampouco, a negação de sua relevância, acreditamos que ele precisa ser ampliado. Já que a literatura é "sistema composto de tantos outros sistemas" (COSSON, 2014, p. 34), é necessário "repensar sua abertura, estabelecendo parâmetros menos centralizados, procurando respeitar a diversidade e as diferentes tradições literárias” (BUSE, 2011, p. 9).

Ainda nessa linha, Cosson (2014) defende que as obras, além de diversificadas, precisam ser atuais, o que não diz respeito, necessariamente, a produções contemporâneas. De acordo com Cosson (2014), as produções contemporâneas são aquelas escritas e publicadas no momento histórico e social do leitor; por sua vez, as atuais são "aquelas que têm significado para mim em meu tempo, independentemente da sua época de sua escrita ou publicação" (COSSON, 2014, p. 34). Com base nesse exposto, acreditamos ser importante incluir, no corpus de produções líricas, o slam, o qual, ao mesmo tempo que é contemporâneo, é atual, ao tratar de questões sociais recorrentes em várias gerações, como buscamos mostrar nas conceitualizações a seguir.

\section{O conceito de Poetry Slam}


Na língua inglesa, slam corresponde a uma onomatopeia usada para indicar o som de uma "'batida' de porta ou janela, seja esse movimento leve ou abrupto", próximo ao "pá!" da língua portuguesa (NEVES, 2017, p. 93). Nos EUA, o termo, inicialmente, era usado apenas em referência aos finais de torneios de beisebol, tênis, basquete e bridge. Depois, seu sentido ampliou-se, quando foi empregado, em 1984, por Marc Kelly Smith, um homem branco, operário de construção civil e poeta, em um evento poético chamado Uptown Poetry Slam, que aconteceu em um bar de jazz, "situado na vizinhança de classe trabalhadora branca no norte de Chicago, nos Estados Unidos” (D’ALVA, 2011, p. 20).

Atualmente, esse evento é considerado o primeiro Poetry Slam de que se tem notícia. Naquele lugar, Smith e outros artistas buscavam, com noites de performances poéticas, tornar a poesia um gênero mais popular, em oposição aos fechados círculos acadêmicos nos quais ela era praticada. Existente até hoje, no mesmo bar, nas noites de domingo, o Uptown Poetry Slam cresceu e difundiu-se para outras cidades dos Estados Unidos. Seu desenvolvimento foi tão rápido que, em 1990, ocorreu o primeiro National Poetry Slam, na cidade de São Francisco, e, posteriormente, em 2002, o primeiro campeonato internacional em Roma, Itália. Na ocasião, os poetas apresentaram-se em suas línguas nativas com traduções simultâneas numa grande tela atrás deles.

No Brasil, o Poetry Slam chegou em dezembro de 2008, quando Roberta Estrela D' Alva fundou o ZAP! Slam (Zona Autônoma da Palavra), promovido na cidade de São Paulo, toda segunda quinta-feira do mês, com exceção de janeiro. Em 2012 Emerson Alcalde fundou o segundo slam do Brasil, na Zona Leste de São Paulo, o Slam da Guilhermina, que, também com a ressalva de janeiro, acontece todas as últimas sextas-feiras de cada mês, a partir das 20h, na praça Guilhermina-Esperança, ao lado da estação do metrô. Esses slams, em geral, são compostos de dez batalhas ao longo do ano, de fevereiro a novembro; em dezembro, realiza-se a batalha 
final com a presença do ganhador de cada mês. O vencedor de todos os slams do país disputa uma vaga no Campeonato Nacional de Poetry Slam, o Slam Br., evento em que se define quem vai representar o Brasil na Copa do Mundo de Poesia Falada, que acontece em Paris todos os anos.

Nesse contexto, vinte slammers de países diferentes competem entre si em um evento que, além de ser patrocinado pelo governo francês, conta com uma grande divulgação na mídia. Diferente do que acontece no Brasil, “[...] a televisão francesa faz entrevistas com os poetas que vão participar do torneio e as matérias nos jornais chegam a ocupar uma página" (NEVES, 2017, p. 96). Por fim, em âmbito nacional, existe também, desde 2015, o Slam Interescolar de São Paulo. Com os adolescentes das escolas públicas paulistanas como público, há, por meio da ação, uma democratização no que diz respeito ao acesso à poesia, já que os jovens, além de se tornarem leitores, passam a escrever poesia, com versos capazes de tematizar criticamente a realidade (NEVES, 2017).

Portanto, de 1984 até os dias atuais, há diversas batalhas de poesia ocorrendo no Brasil, ${ }^{3}$ bem como em diferentes países. Devido a isso, de acordo com D'Alva (2011, p. 109), uma das poucas estudiosas do slam no meio acadêmico brasileiro, torna-se complicado defini-lo de modo simplificado:

Poderíamos definir o poetry slam, ou simplesmente slam, de diversas maneiras: uma competição de poesia falada, um espaço para livre expressão poética, uma ágora onde questões da atualidade são debatidas ou até mesmo mais uma forma de entretenimento. De fato, é difícil defini-lo de maneira tão simplificada, pois, em seus 25 anos de existência, ele se tornou, além de um acontecimento poético, um movimento social, cultural, artístico que se expande progressivamente e é celebrado em comunidades em todo o mundo.

3 Atualmente, acredita-se que haja, no Estado de São Paulo, cerca de 50 slams. Em uma estimativa geral de 2018, existiam cerca de 150 comunidades em todo o país, com a presença de pelo menos um slam em cada Estado. Informação disponível em: <https://www. profseducacao.com.br/2019/11/12/o-que-e-slam-poesia-educacao-e-protesto/>. Acesso em: 12 maio 2020. 
Apesar disso, D’Alva (2011, p. 113) esclarece a existência de três regras básicas que regem todo e qualquer slam: os poemas devem ser da autoria de quem vai apresentá-los; precisam ter, no máximo, três minutos; e não há a possibilidade de uso de figurinos, adereços ou qualquer tipo de acompanhamento musical na apresentação. Para cronometrar o tempo de cada performance, ${ }^{4}$ há um encarregado, o counter. Quando o slammer, poeta, ultrapassa seu tempo-limite, o counter levanta a mão e, com um sinal, concede mais dez segundos para que ele finalize.

O counter também é responsável por registrar as notas (de zero a dez) atribuídas pelos jurados a cada performance, em uma planilha-controle. Ao todo, o grupo de jurados é composto de cinco pessoas escolhidas aleatoriamente em meio ao público presente, levando-se em consideração a maior diversidade possível. As notas são reveladas ao final de cada poema, por meio de placas que são levantadas individualmente, sem justificativas. Entre as cinco pontuações, a mais alta e a mais baixa são cortadas para que não haja favorecimentos ou desfavorecimentos; das três notas restantes, faz-se a média, e o poeta com a maior pontuação é considerado o campeão da noite.

Ao longo do período de atribuição das notas, o público, geralmente, grita "Credo!" para as notas baixas e, para as altas, "Bom!". Além disso, vaiam quando concordam ou discordam das notas do jurado (NEVES, 2017). No momento em que os enunciados são apresentados, o público também participa inspirando os poetas, por meio de aplausos, batida de pés e interferência com palavras nos poemas. No intervalo entre uma performance e outra, pode haver a apresentação de um DJ ou de um VJ, manipulando imagens ao vivo. Por isso,

O momento presente em que o encontro se dá, não é pas-

\footnotetext{
4 O tempo, no início, garantia que o maior número possível de pessoas participasse do evento. Hoje, sabe-se que é um elemento que influencia na forma e no conteúdo dos poemas (D'ALVA, 2011). Ainda sobre o assunto, existem variações em relação à duração de três minutos. Como exemplo, há o Slam do Corre, em que os poemas devem ter, no máximo, 10 segundos.
} 
sível de reprodução, e muito embora existam registros dos campeonatos e até mesmo livros de antologias com os poemas que são recitados, nada substitui a presença física, o encontro, o diálogo entre as diferenças, ponto central desse tipo de manifestação (D’ALVA, 2011, p. 121).

Ainda em relação ao público, o ZAP! Slam e o Slam da Guilhermina, em uma noite, reúnem entre duzentas e trezentas pessoas. Nesse número, de acordo com Stella (2015), existe o "público cativo", que é formado por frequentadores habituais das batalhas de poesia, sendo, a maior parte, amigos dos poetas ou dos organizadores do evento. Há, também, os moradores da região ou das proximidades bem como o "público passante", composto de curiosos, ou seja, pessoas que apenas estão transitando pela região e decidem parar para escutar um pouco de poesia.

Sobre o teor do que será avaliado, destaca-se que os jurados devem ater-se ao texto e também à "autoperformance" do slammer, a saber, à capacidade de ele incorporar o poema de sua autoria. Por não poder contar com adereços, figurinos ou acompanhamento musical, os poetas usam da modulação da voz e do corpo para proporcionar efeitos semelhantes aos de possíveis subterfúgios cênicos. Dessa forma, "alguns poetas declamam no palco, alternando o uso ou não do microfone; outros caminham por entre a plateia, gesticulam, gritam e silenciam [...]” (NEVES, 2017, p. 102-103).

Além desses aspectos, deve-se esclarecer que a poesia é o elemento principal nos slams. O objetivo é sua popularização, não cabendo a exaltação de melhores poetas. Por isso, o termo "comunidade" é o que melhor define os grupos que "praticam" o Poetry Slam, "já que esses vêm se organizando coletivamente em torno de um interesse comum, sob um conjunto mínimo de normas e regras" (D’ALVA, 2011, p. 121). Como exemplos, temos o Slam das Minas, onde apenas mulheres participam, e o Slam do Corpo, composto de pessoas surdas, ouvintes e intérpretes. As organizações não têm custos para usar as informações de outras diferentes comunidades; pelo contrário, o diálogo e o trânsito de informações 
são muito incentivados. Ainda dentro dessa perspectiva, não há estímulo à produção de "super stars", com a glorificação de determinados poetas em detrimento de outros, porque, caso isso acontecesse, estaríamos diante de um spoken word. ${ }^{5}$

Quanto à temática, os slams, com marca grande de oralidade e informalidade, exibem assuntos que se remetem ao grupo social ao qual cada poeta pertence. Existe uma tendência para temas aliados a causas sociais, dentre os quais estão o feminismo, o empoderamento das mulheres, a autoafirmação feminina, o racismo e as pautas de visibilidade negra, assim como os que se relacionam à sexualidade, ao movimento LGBTQIA+, aos direitos das pessoas com deficiências, ao anticapitalismo e às causas ambientais.

Apesar de esses temas serem mais comuns, os slammers podem trazer os assuntos que desejarem, sendo a vida dos poetas e suas vivências grandes aliadas do conteúdo das produções. A título de exemplo, Mariana Felix e Lucas Afonso, em Se é amor que você quer ${ }^{6}$ abordam tematicamente as diferenças no relacionamento amoroso. Para isso, a produção, com poeticidade, mescla dois eu-líricos, um masculino e outro feminino, e utiliza-se da comparação e metalinguagem ("Ela escreve/Eu escravo/Ela tem métrica/Eu só faço em verso"), da sinestesia ("Se é amor que você quer/Recebe!/Me bebe, sou drink que quiser/Mistura de montila com guaraná/Eu gosto mesmo é quando a dança é de par/Quando as coxas se encostam”), da coloquialidade (“E cá pra nós/Já nem está tão barata”), dentre outros recursos.

No entanto, pelas temáticas e pelo cunho político em geral, esse tipo de produção pode ser considerado de resistência, a qual se dá por meio da atitude de não ceder às imposições dos sistemas político, econômico ou

$5 \quad$ Spoken word faz referência a um tipo de poesia falada, na qual a ênfase encontra-se no poema, que pode ser registrada e comercializada na indústria fonográfica (D’ALVA, 2011). Um slammer que passou a ser um ícone da indústria cultural é o Grand Corps Malade, que já vendeu mais de 18 dvds, todos com uma tiragem expressiva (MIRANDA, 2015).

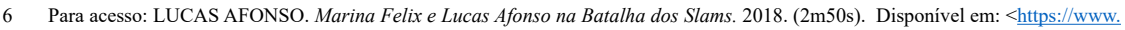
youtube.com/watch?v=sFGfyT87MXo >. Acesso em: 12 maio 2020. 
social, que, por meio de suas forças, acabam marginalizando todos aqueles que não se enquadram nos padrões impostos. Por outro lado, os lugares onde ocorrem essa manifestação poética também constituem um ato de resistência: ao invés de acontecer em locais fechados, centrais e restritos, ela é localizada, de forma gratuita, nas ruas e, principalmente, na periferia.

Nesse lugar à parte das áreas centrais, o slam acaba representando não apenas a posição de um sujeito individual mas de toda uma dada comunidade. Nessa direção, cabe esclarecer que seu sentido, além de refletir a realidade, atua como uma ferramenta histórico-cultural, posto que o texto produzido "não é o produto final da atividade criativa, mas um ato de intervenção e participação na vida da comunidade onde ele se produz e circula" (OLIVEIRA, 2011, p. 34). Nesse sentido, por meio das batalhas poéticas, o slam permite que a periferia conte e escreva "a própria experiência, em contraponto à cultura oficial dominante" (OLIVEIRA, 2011, p. 34).

Ao ser levado à sala de aula, o slam pode proporcionar o debate de diversas questões contemporâneas e, por consequência, contribuir para o desenvolvimento do pensamento crítico dos alunos, oferecendo-lhes, inclusive, voz e expressão na forma de produção. Com o potencial de ser um meio de empoderamento individual, ele pode romper com a timidez e aprimorar a capacidade expressiva, assim como a criatividade dos discentes, fortalecendo, de tal forma, sua identidade e autoestima. Na escrita, a argumentação também pode ser exercida, visto que o texto precisa ser defendido por quem escreve.

Nesse viés, encontram-se estudos acadêmicos resultantes de propostas de intervenção em sala de aula com o slam. Por exemplo, em sua dissertação de mestrado, Dantas (2019, p. 132), devido a um trabalho desenvolvido com alunos do $9^{\circ}$ ano do Ensino Fundamental II, assinala o "envolvimento, a dedicação, a coragem e o esforço de todos os alunos que participaram, mesmo daqueles que a princípio resistiram à proposta”. Já Viana (2018, p. 123), por meio de uma experiência de escrita com uma tur- 
ma de $6^{\circ}$ ano, constatou, ao analisar as produções de seus "jovens poetas", que "os alunos tiveram a oportunidade de exteriorizar, no contexto escolar, suas ideologias e visões de mundo, construídas a partir do que refletem e refratam dos diferentes discursos que os rodeiam, sob os quais estão expostos, enquanto sujeitos sociais".

Diante desses argumentos sobre a importância do slam e da possibilidade de sua presença no ensino regular, alguns questionamentos podem surgir, tais como: como levar efetivamente o slam para a sala de aula e por onde começar o seu ensino? Na tentativa de respostas, propomos, a seguir, uma sequência básica nos moldes sugeridos por Cosson (2014), na perspectiva do letramento literário, para o trabalho com o slam.

\section{O slam na sala de aula: uma proposta didática}

Conforme sintetizam Souza e Cosson (2013), a escrita atravessa a nossa existência das mais diversas maneiras. Levando-se em consideração contextos diversificados, a leitura e a produção textual relacionam-se com diferentes práticas sociais, e, para cada uso que fazemos da escrita em sociedade, passou-se a usar o termo "letramento". Devido a isso, a palavra no plural - "letramentos" - parece ser mais adequada para que possamos "abranger toda a complexidade dos meios de comunicação de que, hoje, dispomos" (SOUZA; COSSON, 2013, p. 102). Por meio de tal ótica, entende-se que um sujeito pode ter um grau sofisticado de letramento em uma determinada área e um conhecimento superficial em outra, "dependendo de suas necessidades pessoais e do que a sociedade lhe oferece ou demanda" (COSSON, 2014, p. 12). Nesse sentido, o letramento literário corresponderia mais a uma prática social.

Contudo, diferente de outros letramentos, o literário "tem uma relação diferenciada com a escrita e, por consequência, é um tipo de letramento singular" (SOUZA; COSSON, 2013, p. 102). Essa particulari- 
zação refere-se, fundamentalmente, ao modo privilegiado como ocorre a inserção no universo da produção escrita: nos textos literários, o domínio da palavra se dá por meio dela mesma. Outra distinção encontra-se no fato de que, para o domínio efetivo do letramento literário, é importante um trabalho escolar processual.

Para isso, a escolarização da literatura não pode ser tratada como uma simples leitura. Ao contrário, e sem deixar o prazer de lado, o seu trabalho exige um compromisso com o saber, que não pode ser assistemático; há a necessidade de um método "para se trabalhar a leitura na escola, compreendendo que todo processo educativo precisa ser organizado para atingir seus objetivos" (COSSON, 2014, p. 13). Nessa direção, o docente pesquisador delineia e sugere a "sequência básica" como um dos possíveis procedimentos para efetivar o letramento literário na sala de aula.

A sequência básica constitui-se de quatro etapas: motivação, introdução, leitura e interpretação (COSSON, 2014, p. 51-75). A etapa de motivação objetiva preparar os alunos para "entrar" na leitura do texto escolhido; trata-se de um momento para se estabelecer laços com a leitura a ser feita, no tempo máximo de uma aula (COSSON, 2014, p. 57). Já a introdução refere-se a uma apresentação do autor e da obra; é uma oportunidade para justificar a escolha do texto e fornecer informações básicas sobre seu autor. Na etapa da leitura, o aluno deve ser acompanhado, por meio de paradas reflexivas e diagnósticas, visto que, considerando-se as dificuldades apresentadas por ele, o professor será capaz de promover intervenções eficientes. Por fim, na interpretação, dentro de uma relação que envolve autor, leitor e comunidade, o momento é de estabelecer inferências para se chegar à construção do sentido do texto. $\mathrm{O}$ resultado da leitura deve, ao final, ser externalizado, por meio de um registro do que foi lido (COSSON, 2014). Com base nesses pressupostos, apresentamos, a seguir, uma proposta concreta de trabalho com o slam para o Ensino Médio enfocando o tema do racismo. A escolha de tal segmento deve-se ao fato de que 
o vocabulário empregado por muitos slammers é, potencialmente, mais bem compreendido pelos alunos de anos escolares finais. No entanto, nada impede que a sequência seja aproveitada em outro segmento de ensino, com as adaptações pertinentes.

Tabela 1 - Proposta de sequência básica para o ensino do slam

\begin{tabular}{|c|c|}
\hline Tema & A aula de literatura como um ambiente colaborativo no combate ao racismo \\
\hline Público-alvo & $1^{\circ}$ ano do Ensino Médio ${ }^{7}$ \\
\hline Objetivos & $\begin{array}{l}\text { Despertar o conhecimento, o prazer e o interesse pelo slam; } \\
\text {. Refletir sobre o racismo, com a finalidade de combatê-lo; e } \\
\text {. Desenvolver a produção escrita, por meio da produção de cartazes. }\end{array}$ \\
\hline Conhecimento prévio & $\begin{array}{l}\text { Uma breve sensibilização poética, com base nos anos anteriores de estudo, a } \\
\text { partir de um conhecimento geral sobre a poesia e sua estrutura. }\end{array}$ \\
\hline Tempo de duração & 3 encontros de duas aulas cada. \\
\hline Materiais & $\begin{array}{l}\text { Um computador conectado a um projetor e a um equipamento de som; } \\
\text { Para a atividade de motivação, quatro fotos, que podem ser impressas ou } \\
\text { projetadas com o apoio do computador; } \\
\text {. Uma cópia impressa do poema para cada aluno da sala; e } \\
\text {. Para a atividade final, cartolinas, tintas, tesoura, cola, canetinhas e demais } \\
\text { materiais que se fizerem necessários para a confecção dos cartazes. }\end{array}$ \\
\hline & Cronograma da sequência básica \\
\hline
\end{tabular}

7 Optamos por especificar o $1^{\circ}$ ano do Ensino Médio, já que a maioria dos materiais didáticos escolhem tratar as características do gênero lírico nesta série, em consonância com uma possível definição para o conceito de literatura. 


\begin{tabular}{|c|c|}
\hline $\begin{array}{l}\text { Motivação e Intro- } \\
\text { dução (Duração: um } \\
\text { encontro com duas } \\
\text { aulas) }\end{array}$ & 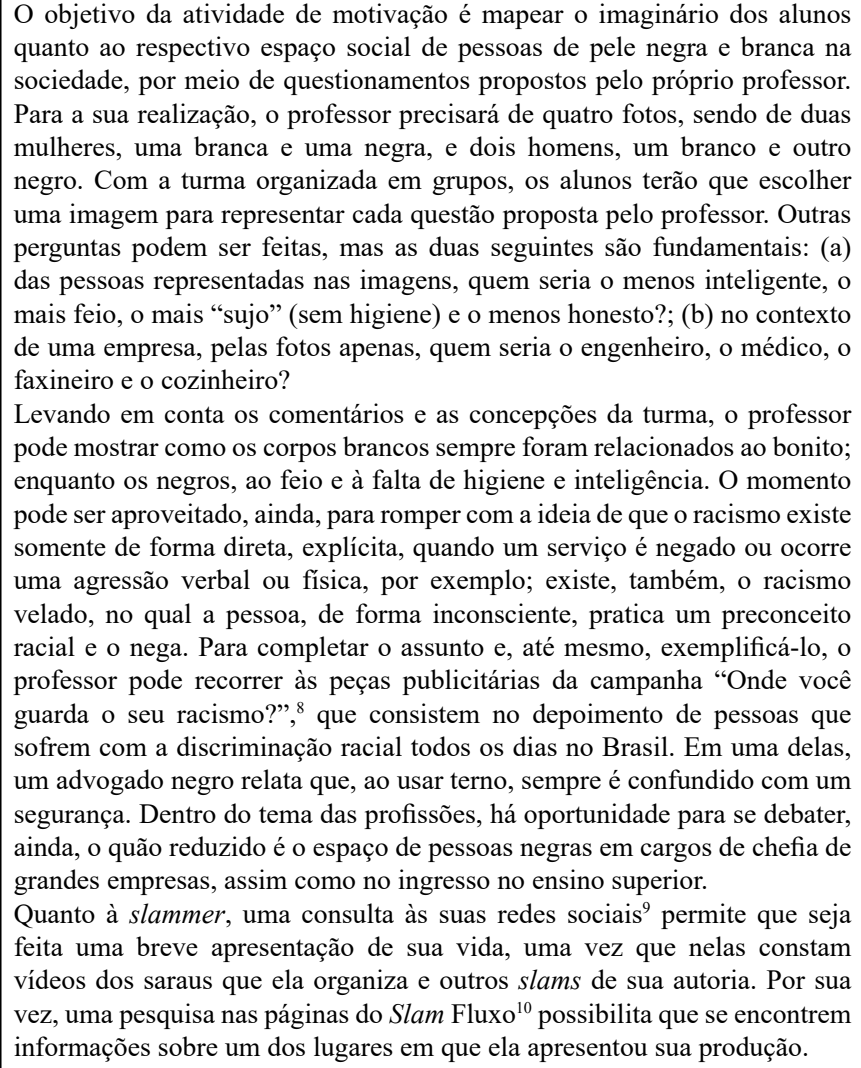 \\
\hline
\end{tabular}

8 Algumas imagens da campanha podem ser encontradas em: <http://observatoriodajuventude.ufmg.br/pactomg/images/ETAPA2/ APOIOCADERNO2/SEQUENCIADIDATICASOCIOLOGIA.pdf>. Acesso em: 12 maio 2020.

9 As redes sociais de Jéssica Campos são: <https://www.facebook.com/JessicaC.Poesia/> e <https://www.instagram.com/jejeh campos/?hl=pt-br>. Acesso em: 12 maio 2020.

10 As redes sociais do Slam Fluxo são: <https://www.facebook.com/pg/slamfluxo/about/?ref=page_internal, <https://www.instagram. com/slamfluxo/?hl=pt-br>. Acesso em: 12 maio 2020. 


\section{Leitura e Interpretação (Duração: um encontro com duas aulas)}

\begin{abstract}
Após a introdução, inicia-se a etapa da leitura. Para sua execução, recomenda-se que os alunos, primeiro, leiam silenciosamente o slam. Em seguida, o professor pode fazer algumas perguntas de compreensão; dentre elas, sugerimos que o professor questione sobre o que acharam do texto, qual seria a temática principal da produção e se conseguem imaginar como seria a performance que a slammer deu ao seu texto. Caso algum aluno queira apresentar uma possível performance dada ao poema, esse seria o momento ideal.
\end{abstract}

Com todas essas hipóteses criadas, a sequência avança para a etapa de intepretação. Nesse momento, recomendamos que o professor exiba o vídeo no qual Jéssica Campos apresenta o seu poema, no contexto de uma batalha do Slam Fluxo.

Logo após a exibição do vídeo, a interpretação pode começar pelas temáticas presentes no texto. Dentre elas, estão o embranquecimento cultural ("Parem de querer embranquecer o meu legado/Entenda: eu não sou uma vírgula na sua cultura/Eu sou ponto e vírgula, exclamação/Eu sou a transversão dessa escondida apropriação"); a comédia como um meio de propagação de atitudes racistas ("Eu não sou racista/ Então, tira da sua lista todos os comentários imundos e piadas sem graça"); a apropriação cultural ("O problema não é usar/O problema é não saber a história por trás da chamada moda/Em branco é bonito, mas em preta é foda"); a representação do negro na TV ("Eu estou cansada de aplaudir novela na semana/Como se preta protagonista, sempre empregada, fosse bacana"), a Globeleza ("Mas e a Globeleza e a representatividade da mulher negra/Representa... o samba, a mulher do corpo de primeira, da feita para agarrar estrangeiros/A moça da cor do pecado, a preta de bunda grande e peito estufado/A carne mais barata do mercado"); o sentido dado ao corpo da mulher negra ("Eu cansei de 'ocês' acharem que preta só presta no Redtube"); a constante negação do racismo pela sociedade ("Eu cansei de tudo nessa lista/mas, principalmente, do seu não sou racista"). Em relação ao trabalho estético com a linguagem, os alunos devem perceber a presença de um coloquialismo (no uso do "ocês", e na repetição de palavras, como "problema", na escolha de termos como "foda", "bacana", "bunda"), de uma metrificação variada, do uso de versos livres ("O problema não é usar/ O problema é não saber a história por trás da chamada moda") e rimados ("O breaking, o rasta, o dread, os turbantes são meus, mas parece que você não percebeu/Usa como se fosse seu”) etc.

Destaca-se que, nesse momento de interpretação, o professor deve, também, problematizar a performance feita pela poeta, em vez de tratar o slam como se fosse um texto somente escrito. Nesse sentido, deve-se considerar igualmente a importância de se ouvir o que as mulheres negras têm a dizer, sendo elas a parcela mais vulnerável da sociedade.

Em relação à lição para casa, o professor pode solicitar que os alunos ouçam a música "Negão", de Chico César, ${ }^{11}$ e, por meio de uma produção textual, estabeleçam uma comparação entre o poema e a música. 
Produção do gênero textual cartaz (um encontro com duas aulas)
Para terminar as atividades da sequência, a sala poderá confeccionar cartazes, como um meio de externar a leitura do slam. Os cartazes produzidos podem ser espalhados pela escola, com mensagens de combate ao racismo e busca pela igualdade racial. Na parte escrita, os alunos podem recorrer a frases/ pensamentos de pessoas famosas sobre o assunto e/ou pesquisar outras letras de músicas ou poemas para reproduzir na cartolina. O professor pode, também, estimular os estudantes a escrever poemas de autoria própria, com base na estrutura textual do slam, produção poética estudada.

\section{Considerações finais}

Embora o gênero lírico tenha recebido, no decorrer da história, novas definições e sentidos, sempre esteve associado ao desenvolvimento do ser e da sociedade. No contexto escolar, a dificuldade de seu ensino é tema recorrente em diversos trabalhos, seja por sua presença escassa na sala de aula ou pelo teor meramente pedagógico das atividades elaboradas para o seu ensino.

Nessa direção, tendo em vista os textos escolhidos para compor propostas didáticas para o ensino de literatura, e sem questionar a importância do cânone e seu ensino, propusemos a ampliação de seu corpus. Para tanto, e observando o contexto social e suas demandas, apresentamos, dentro da esfera lírica, o slam. Por fim, com a finalidade de diminuir as lacunas ainda existentes no trabalho com o texto literário em sala de aula, elaboramos uma proposta para o ensino do gênero que reforça o estímulo escolar no combate ao racismo, tendo como parâmetro a sequência básica proposta por Cosson (2014), por sua vez, fundamentada no letramento literário.

Por fim, nosso objetivo não foi oferecer uma receita pronta a ser aplicada caso o professor anseie por um trabalho bem sucedido com o slam, mas, em resposta ao título deste trabalho, mostrar que o ensino da literatura pode ocorrer com a apreciação de obras de sistemas literários diversos (COSSON, 2014). Além disso, buscamos evidenciar que, com princípios metodológicos e teóricos, a escolarização da literatura pode confi- 
gurar um processo muito produtivo e enriquecedor, satisfazendo, assim, a necessidade universal de o ser humano ter contato com alguma espécie de fabulação (CANDIDO, 2017), além de atuar de modo fundamental na formação do indivíduo, ao humanizá-lo, e apresentar o real em sua totalidade.

\section{Referências}

BUSE, Bianca. A disciplina de Literatura no Ensino Médio e a (de)formação do leitor. In: ANAIS DO VI COLÓQUIO ENSINO MÉDIO, HISTÓRIA E CIDADANIA v. 1, n. 1, 2011, Florianópolis. Anais [...]. Florianópolis: UDESC/FAED/Grupo de Pesquisa Sociedade, Memória e Educação, 2011, p. 1-13.

CANDIDO, Antonio. O direito à literatura. In: . Vários escritos. 6. ed. Rio de Janeiro: Outro sobre azul, 2017. p. 171-193.

COSSON, Rildo. Letramento Literário: teoria e prática. São Paulo: Contexto, 2014.

D’ALVA, Roberta Estrela. Um microfone na mão e uma ideia na cabeça - o poetry slam entra em cena. Synergies Brésil, Pelotas, n. 9, p. 119-126, 2011.

DANTAS, Lucimar Américo. Poetry Slam: uma experiência com a linguagem poética e seus vínculos com a cultura e a vida. 2019. 265f. Dissertação (Mestrado Profissional em Letras) - Universidade Federal de Uberlândia, Uberlândia, 2019.

ELIOT, Thomas Stearns. A função social da poesia. In: . A essência da poesia: estudos \& ensaios. Trad. Maria Luiza Nogueira. Rio de Janeiro: Artenova, 1972. p. 28-43.

FAILLA, Zoara (org.). Retratos da leitura no Brasil 4. Rio de Janeiro: Sextante, 2016.

GEBARA, Ana Elvira Luciano. O poema, um texto marginalizado. In: BRANDÃO, Helena; MICHELETTI, Guaraciaba. Aprender e ensinar com textos didáticos e paradidáticos. 4. ed. v. 2. São Paulo: Cortez, 2002. 
p. 143-166.

GRASSI, Marilu. Uma sequência didática do gênero poema: desafios e possibilidades para o letramento literário. 2015. 110 f. Dissertação (Mestrado Profissional em Letras) - Universidade Estadual do Oeste do Paraná, Cascavel, 2015.

MARTHA, Alice Áurea Penteado. Literatura infantil: a poesia. In: FERREIRA, Eliane Aparecida Galvão Ribeiro et al (org.). Formação de mediadores de leitura: módulos 1 e 2. Assis: ANEP, 2015. p. 115-130. MIRANDA, Claudia de Azevedo. Aubervilliers e cooperativa: o olhar pós-urbano da periferia sobre a cidade. 2015. 122 f. Dissertação (Mestrado em Letras) - Pontifícia Universidade Católica do Rio de Janeiro, Rio de Janeiro, 2015.

MOISÉS, Carlos Felipe. Poesia não é dificil: introdução à análise do texto poético. Porto Alegre: Artes e Ofícios, 1996.

NEVES, Cynthia Agra de Brito. Slams: letramentos literários de reexistência ao/no mundo contemporâneo. Linha D’Água, São Paulo, v. 30, n. 2, p. 92-112, out. 2017.

OLIVEIRA, Rejane Pivetta de. Literatura marginal: questionamentos à teoria literária. Ipotesi, Juiz de Fora, v. 15, n. 2 - Especial, p. 31-39, jul/dez. 2011.

PAIXÃO, Fernando. O que é poesia. 3. ed. São Paulo: Brasiliense, 1984. PINHEIRO, Hélder. Poesia na sala de aula. Campina Grande: Bagagem, 2007.

SÃO PAULO (Estado). Proposta Curricular do Estado de São Paulo: linguagens, códigos e suas tecnologias. Coordenação de Maria Inês Fini e Alice Vieira. 2. ed. São Paulo: Secretaria da Educação, 2011.

SANTOS, Sandro Prado. Diálogos contra o racismo: o valor da diferença. Portal do Professor, dez. 2009. Disponível em: <http://portaldoprofessor. mec.gov.br/fichaTecnicaAula.html?aula=15375>. Acesso em: 12 maio 2020 . 
SOUZA, Renata Junqueira de; COSSON, Rildo. Letramento literário: uma proposta para a sala de aula. São Paulo: UNESP/UNIVESP, 2013, p. 101-107. Disponível em: http://www.acervodigital. unesp.br/bitstream/123456789/40143/1/01d16t08.pdf. Acesso em: 28 maio 2020.

STELLA, Marcello Giovanni Pocai. A batalha da poesia: o slam da Guilhermina e os campeonatos de poesia falada em São Paulo. Ponto Urbe - Revista do núcleo de antropologia urbana da USP, São Paulo, n. 17, p. 1-18, dez 2015.

VIANA, Lidiane. Poetry slam na escola: embate de vozes entre tradição e resistência. 2018. 165 f. Dissertação (Mestrado Profissional em Letras) Faculdade de Ciências e Letras, Universidade Estadual Paulista (UNESP), Assis, 2018.

WALTY, Ivete. Reflexões sobre a poesia. In: PAULINO, G.; WALTY, I. (org.). Teoria da Literatura na Escola. Belo Horizonte: Editora Lê, 1994. p. $85-93$.

Artigo recebido em: 31/05/2020

Aprovado em: 30/07/2020 